\title{
STUDI PENGARUH LEBAR SUNGAI TERHADAP KARAKTERISTIK ALIRAN SEDIMEN DI DASAR
}

\author{
U. H. Mattotorang ${ }^{1)}$ \\ 1) Dosen Program Studi Teknik Sipil, Universitas Andi Djemma, Palopo \\ 1) hamzahumar2014@gmail.com
}

\begin{abstract}
Abstrak
Pengetahuan tentang transportasi sedimen oleh aliran akan memiliki arti penting untuk pengembangan dan pengelolaan sumber daya air, konservasi tanah, dan perencanaan pembangunan gedung di sungai dan di saluran terbuka. Untuk menganalisisnya, perlu dilakukan penelitian yang menggabungkan dengan masalah kecepatan sedimentasi. Penelitian ini dilakukan dengan membuat aliran yang akan digunakan dalam proses transportasi sedimen (bed load transport). Kemudian dilanjutkan dengan menganalisis hubungan antara dimensi sungai dengan karakteristik aliran sedimen yang terjadi di dasar sungai. Hasil ini menunjukkan bahwa pada penampang saluran yang kecil terdapat kecenderungan untuk mengalami gerusan dasar dan dimensi seluran yang lebih luas rentan terhadap pengendapan sedimen. Perhitungan debit sedimen dengan pendekatan Duboy menunjukkan nilai bed bed (qb) yang diangkut pada saluran 1 dan saluran 3 dengan lebar dasar masing-masing $30 \mathrm{~cm}$ dan $40 \mathrm{~cm}$ dengan gerusan pada saluran 1 adalah 10.59905 (cm3 / dtk) dan 2, 24893614 (cm3 / dtk) untuk saluran 3. Untuk saluran 2 dan saluran 4 dengan lebar $60 \mathrm{~cm}$ dan $70 \mathrm{~cm}$ pengendapan sedimen terjadi $\mathrm{m} 30,003534$ dan 0,016647 untuk saluran 2 ke saluran $4 \mathrm{~m}$. Dari hasil ini dapat dilihat bahwa gerusan pada saluran 1 lebih besar dari gerusan 3 saluran dan pengendapan pada saluran 4 lebih besar dari pengendapan pada saluran 2 .
\end{abstract}

Kata Kunci: pasir putih, pasir biasa, mortar, kuat tekan

\section{PENDAHULUAN}

Sungai merupakan suatu unsur alam yang sangat berperan dalam memenuhi kebutuhan hidup bagi umat manusia. Ketersediaan air dan potensi-potensi lain yang dikandung oleh sebuah sungai, menarik manusia untuk memanfaatkannya. Dalam upaya pemanfaatan potensi sungai tersebut, manusia tidak akan lepas dari konsekuensi untuk melakukan rekayasa sumber daya agar lebih banyak mengambil manfaatnya.

Saat ini, sebagian daerah aliran sungai di Indonesia mengalami kerusakan akibat dari eksploitasi oleh manusia dan juga oleh karakteristik aliran sungai itu sendiri. Debit dan kecepatan aliran yang besar menyebabkan gerusan pada tebing dan dasar sungai. Hal tersebut memicu proses penggerusan/erosi dan endapan/deposisi dalam tubuh sungai. Dalam keadaan yang parah, hal ini dapat menyebabkan longsoran (sliding) dengan massa yang besar pada tebing sungai dan dapat menyebabkan kerusakan pada infrastruktur yang ada. Ekspansi (pelebaran) dimensi sungai dapat menyebabkan perubahan karakteristik aliran seperti perubahan tinggi energi, kecepatan aliran, dan debit. Dengan berubahnya perameter tersebut, maka akan terjadi pula perubahan karakteristik angkutan sedimen di dasar sungai. Perubahan karakteristik angkutan sedimen di dasar ini ditandai dengan berubahnya kecepatan angkutan sedimen di dasar dan debit sedimen dasar (bed load).

\section{Erosi dan Sedimen.}

Erosi dan sedimentasi merupakan proses terlepasnya butiran tanah dari induknya dari suatu tempat dan terangkutnya material tersebut oleh gerakan air atau angin kemudian diikuti oleh pengendapan material yang terjadi di tempat lain.(Suripin. 2002). 
Sedimen adalah material dari hasil proses erosi, baik berupa erosi permukaan, erosi parit, erosi dasar sungai atau jenis erosi tanah lainnya. Besarannya ditentukan dengan parameter berikut.

1. Rapat massa dan berat jenis

Rapat massa pasir dan mineral tanah pada umumnya diambil sekitar $\rho_{s}=2650$ $\mathrm{kg} / \mathrm{m}^{3}$, sedangkan berat jenis didefinisikan sebagai perbandingan rapat massa sedimen dan rapat massa fluida :

$\mathrm{S}=\frac{\rho_{s}}{\rho}=2,65$

2. Ukuran butiran partikel sedimen

Dalam permasalahan dinamika dan perilaku sedimen, ukuran butiran material sedimen merupakan salah satu parameter yang sangat penting. Ukuran butiran merupakan salah satu faktor yang menentukan mudah tidaknya serta banyak sedikitnya sedimen akan mengalami mekanisme transpor.

Jenis-Jenis Sedimen.

Sedimen dapat diklasifikasikan ke dalam 2 bagian yaitu berdasarkan mekanisme pengangkutannya dan bersarkan asalnya.

a. Menurut mekanisme pengangkutannya dapat dibedakan menjadi 2 (dua) macam, yaitu:

Muatan dasar (bed load)

Pergerakan partikel di dalam aliran air sungai dengan cara menggelinding, meluncur dan meloncat-loncat di atas permukaan dasar sungai.

Muatan melayang (suspended load).

Terdiri dari butiran halus yang senantiasa melayang di dalam aliran sungai. Kecenderungan partikel untuk mengendap selalu terkompensasi oleh aksi difusif dari aliran turbulen air sungai.

b. Menurut asalnya, bahan-bahan dalam angkutan sedimen dapat dibedakan menjadi 2 (dua) macam, yaitu :

\section{Bed material transport}

Merupakan bahan angkutan yang berasal dari dalam tubuh sungai itu sendiri dan ini dapat diangkut dalam bentuk muatan dasar ataupun muatan melayang.

Wash load

Merupakan bahan angkutan yang berasal dari sumber-sumber diluar tubuh sungai yang tidak ada hubungannya dengan kondisi lokal. Bahan angkutan ini berasal dari hasil erosi di daerah aliran sungainya (DAS). Bahan ini hanya bisa diangkut sebagai muatan melayang dan umumnya terdiri dari bahan- bahan yang sangat halus $<50 \mu \mathrm{m}$.

\section{Gerusan}

Menurut (Setyono, 2007) Gerusan adalah perubahan dari suatu aliran yang disertai pemindahan material melalui aksi gerakan fluida.Atau dapat dikatakan juga bahwa gerusan adalah merupakan erosi pada dasar dan tebing saluran alluvial.

\section{Ukuran Butiran Dan Kecepatan Aliran}


Kecepatan fluida dimana partikel akan naik ke dalam aliran dapat disebut sebagai kecepatan kritis. Jika gaya yang bekerja pada partikel di dalam aliran telah dibahas, maka hubungan sederhana antara kecepatan kritis dan massa partikel dapat diperkirakan. Gaya seret (drag force) yang diperlukan untuk menggerakkan partikel di sepanjang aliran akan meningkat seiring massa, karena akan memerlukan gaya angkat untuk membawa partikel naik ke dalam aliran. Pada kecepatan sedang (moderate) butir pasir dapat tersaltasi, butiran bergerak rolling dan kerakal tetap tidak bergerak, tapi jika kecepatan meningkat gaya yang bekerja pada partikel-partikel ini bertambah dan pasir lebih halus mungkin tersuspensi, butiran tersaltasi, dan kerakal bergerak rolling. Hubungan linear sederhana seperti ini juga bekerja untuk material lebih kasar, tapi ketika ukuran butir halus terlibat maka akan semakin komplek.

\section{Debit Angkutan Dasar ( Bed Load).}

Sungai akan stabil apabila tidak terjadi erosi pada dasar maupun tebing sungai. Tegangan geser yang terjadi di dasar maupun tebing sungai disebabkan oleh aliran sungai. Apabila tegangan geser yang terjadi di dasar sungai $(\tau b)$ lebih- besar dari tegangan kritis $\left(\tau_{0}\right) c r$, maka akan terjadi erosi. Tegangan geser kritis yaitu tegangan geser yang terjadi pada saat butiran dasar /tebing sungai mulai bergerak.

Ada beberapa persamaan yang biasa digunakan untuk menghitung besarnya tegangan geser kritis. Schoklitsch (1914) mengusulkan persamaan berdasarkan hasil penelitiannya sebagai berikut :



Dimana :



$=$ Diameter sedimen $(\mathrm{mm})$

\section{Persamaan Du Boy}

Besar persamaan Du Boy dapat dilihat sebagai berikut :

$\mathrm{qb}=\frac{0,173 \tau(\tau-\tau \mathrm{c})}{\mathrm{d}^{3 / 4}}$

\section{Aliran Air di Saluran Terbuka}

Aliran air dapat terjadi pada saluran terbuka maupun pada saluran tertutup (pipe flow). Pada saluran terbuka, aliran air akan memiliki suatu permukaan bebas yang berkaitan langsung dengan parameter-parameter aliran seperti, kecepatan, kekentalan, gradien dan geometri saluran.

\section{Penentuan Unsur Geometrik}

Unsur-unsur geometrik pada saluran terbuka antara lain:

1. Kedalaman aliran (y) adalah jarak vertikal titik terendah pada suatu penampang saluran sampai ke permukaan bebas.

2. Lebar puncak ( $\mathrm{T}$ atau $\mathrm{b}$ ) adalah lebar penampang saluran pada permukaan bebas.

3. Luas basah (A) adalah luas penampang melintang aliran yang tegak lurus dengan arah aliran. 
4. Keliling basah (P) adalah panjang garis perpotongan dari permukaan basah saluran dengan bidang penampang melintang yang tegak lurus arah aliran.

5. Jari-jari hidrolik (R) adalah Rasio luas basah dengan keliling basah

$\mathrm{R}=\frac{A}{P}$

6. Kedalaman Hirolik (D) adalah rasio luas basah dengan lebar puncak

$\mathrm{D}=(3 / 4) * \mathrm{~h}$

\section{Penentuan Kecepatan aliran}

Penggunaaan rumus manning:

$\mathrm{V}=\frac{S^{0,5} * R^{2 / 3}}{n}$

Dimana:

$\mathrm{V}=$ Kecepatan rata-rata $(\mathrm{m} / \mathrm{s})$

$\mathrm{R}=$ Jari-jari hidrolik $(\mathrm{m})$

$\mathrm{S}=$ Kemiringan/ slope

$\mathrm{n}=$ koefisien kekasaran

\section{METODOLOGI PENELITIAN}

\section{Penelitian Secara Fisik}

Dilaksanakan di laboratorium untuk mengamati serta mencatat fenomena yang ada pada model yang meliputi studi literatur, persiapan alat dan bahan, perencanaan model dan simulasi, pembuatan model, percobaan pendahuluan, simulasi dan pengambilan data.

\section{Penelitian Secara Hipotetik dan Analitik}

Hal ini dilakukan untuk mendapatkan hubungan antara variabel yang saling terkait. Dalam hal ini meliputi analisis data, pembahasan, pembuatan kesimpulan, hingga penyusunan laporan.

\section{Jenis Penelitian}

Adapun jenis penelitian yang digunakan adalah eksperimen laboratorium. Menurut Moh. Nasir, Ph.D (1988) observasi dibawah kondisi buatan (artificial condition), dimana kondisi tersebut dibuat dan diatur oleh peneliti. Dengan demikian penelitian eksperimental adalah penelitian yang dilakukan dengan mengadakan manipulasi terhadap objek penelitian serta adanya kontrol, dengan tujuan untuk menyelidiki ada atau tidaknya hubungan sebab akibat serta berapa besar hubungan sebab akibat tersebut dengan cara memberikan perlakuan-perlakuan tertentu pada beberapa kelompok eksperimen dan menyediakan kontrol untuk perbandingan.

\section{Perolehan Data}

Pada penelitian ini, kami hanya menggunakan satu sumber data, yakni data primer. Data primer, yaitu data yang diperoleh langsung dari pengamatan di laboratorium.

\section{Variabel Yang Diteliti}

Sesuai dengan tujuan penelitian yang telah dikemukakan pada bab sebelumnya, maka variabel yang diteliti adalah kecepatan aliran (v) dan lebar saluran (l). 


\section{Simulasi Model}

Rangkaian simulasi pada penelitian ini dilakukan ngan tiga tahapan pengambilan data. Tahap pertama dilakukan setelah running model dengan lama waktu pengaliran 15 menit, 30 menit dan 45 menit.

Secara garis besar prosedur perolehan data adalah sebagai berikut:

1. Langkah awal adalah melakukan kalibrasi terlebih dahulu pada peralatan percobaan.

2. Selanjutnya sedimen (pasir) diletakkan di tengah-tengah flume, kemudian meratakan sedimen dengan spatula.

3. Setalah flume sudah terisisi sedimen dan rata, selajutnya mengukur tinggi antara sedimen dengan tali pias dari hulu saluran ke-1 sampai hilir saluran ke- 4 hingga di dapat kemiringan yang cukup untuk mengalirkan air dari hulu ke hilir.

4. Setelah semua komponen siap, running dimulai dengan menyalakan pompa sirkulasi terlebih dahulu sampai aliran permukaan pada saluran menjadi stabil.

5. Setelah aliran sudah stabil, maka selanjutnya dilakukan pengukuran kecepatan aliran dengan menggunakan alat flow watch.

6. Matikan pompa dan mulai mengukur elevasi dasar saluran pada titik-titik yang telah disediakan.

7. Mengisi kembali saluran dengan sedimen seperti pada prosedur yang pertama.

8. Sisa air yang kotor dan bercampur sedimen dikeluarkan dari saluran dan bak sirkulasi melalui pipa pembuangan.

\section{HASIL DAN PEMBAHASAN}

\section{Debit Aliran}

Data-data yang diperoleh dari hasil pengukuran di laboratorium seperti, tinggi aliran dan kecepatan aliran di setiaap penampang saluran, dapat menghasilkan sebuah besaran berupa debit aliran, $Q\left(\mathrm{~m}^{3} / \mathrm{s}\right)$. Dengan mengimplementasikan rumus-rumus hidraulik yang sudah ada sebelumnya. Di bawah ini, merupakan beberapa hasil pengukuran yang kami catat pada saat di laboratorium.

Tabel 1. Data lebar dan kedalaman Aliran

\begin{tabular}{|c|c|c|c|c|c|}
\hline \multirow{2}{*}{ Lama pengaliran (menit) } & \multirow{2}{*}{ Lebar saluran (m) } & \multicolumn{3}{|c|}{ Tinggi aliran,h (m) } & \multirow{2}{*}{ Tinggi rata-rata(m) } \\
\hline & & Hulu & Tengah & Hilir & \\
\hline \multirow{4}{*}{15} & 0,3 & 0,065 & 0,065 & 0,065 & 0,065 \\
\hline & 0,4 & 0,065 & 0,065 & 0,065 & 0,065 \\
\hline & 0,6 & 0,61 & 0,61 & 0,61 & 0,61 \\
\hline & 0,7 & 0,061 & 0,061 & 0,061 & 0,06 \\
\hline \multirow{4}{*}{30} & 0,3 & 0,064 & 0,064 & 0,064 & 0,064 \\
\hline & 0,4 & 0,064 & 0,064 & 0,064 & 0,064 \\
\hline & 0,6 & 0,06 & 0,06 & 0,06 & 0,06 \\
\hline & 0,7 & 0,059 & 0,059 & 0,059 & 0,059 \\
\hline \multirow{3}{*}{45} & 0,3 & 0,065 & 0,065 & 0,065 & 0,065 \\
\hline & 0,4 & 0,064 & 0,064 & 0,064 & 0,064 \\
\hline & 0,6 & 0,62 & 0,62 & 0,62 & 0,62 \\
\hline
\end{tabular}




\section{0,7}

0,060

0,060

0,060

0,060

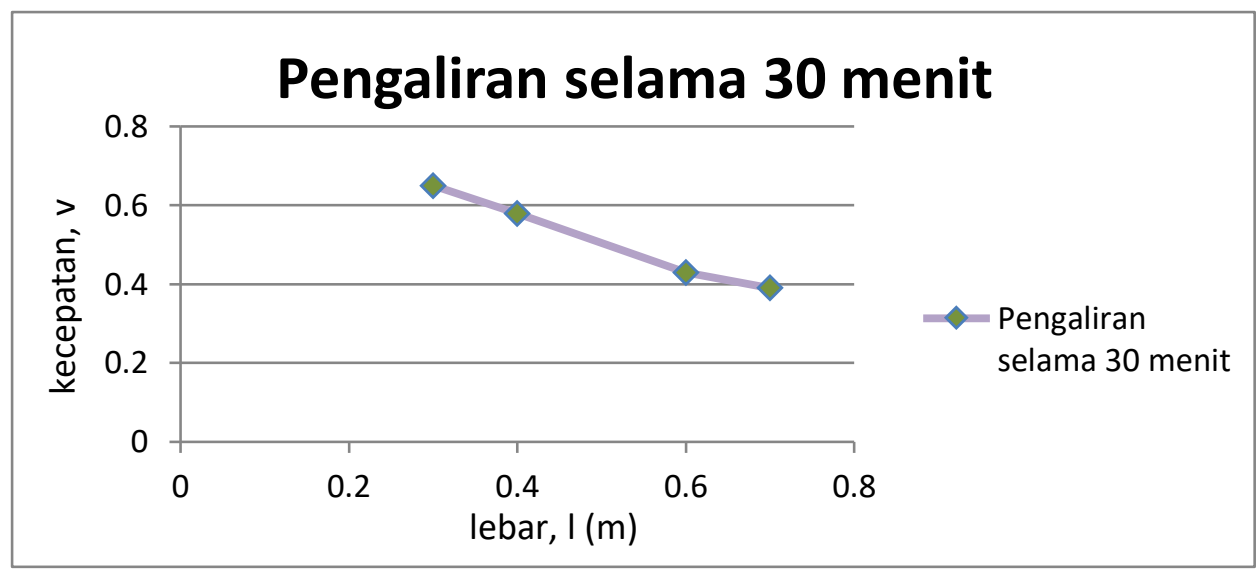

Gambar 1. Grafik Hubungan lebar penampang dengan Kecepatan Aliran $(\mathrm{t}=30$ menit)

\section{Kedalaman dasar saluran setelah pengaliran.}

Kedalam dasar saluran pada saluran 1

Saluran ini merupakan saluran paling hulu. Sehingga, sedimen yang melintas di atas saluran ini hanya berasal dari sedimen bagian hulunya sendiri. Lebar dasar salura ini adalah $30 \mathrm{~cm}$.

Dari data kedalaman dasar saluran dapat diketahui bahwa selama pengaliran terjadi penggerusan di sepanjang dasar saluran 1. Adapun grafik yang kami peroleh dari pengukuran tersebut, dapat dilihat pada gambar di bawah ini

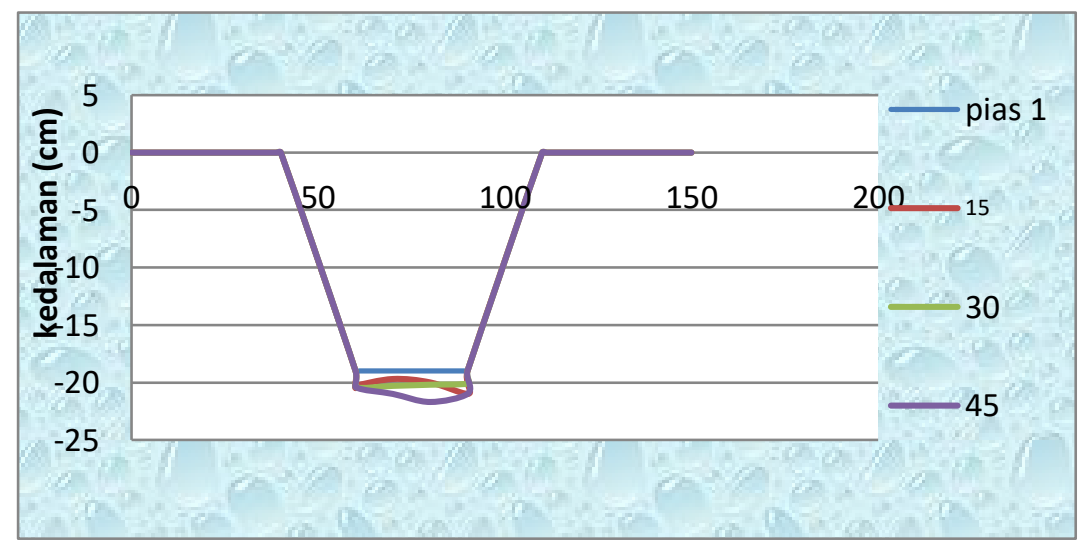

Gambar 2. Grafik kedalaman dasar saluran pada saluran 1 pada bagian hulu

\section{Kedalam dasar saluran pada saluran 2}

Pada saluran 2 ini, terjadi transformasi dimensi penampang saluran dari hilir saluran 1 menuju hulu saluran 2. Dimana dimensi dasar saluran 1 yang memiliki lebar $30 \mathrm{~cm}$ menuju dimensi dasar saluran 2 yang lebarnya $60 \mathrm{~cm}$ yang dalam ilmu hidrolika disebut sebagai ekspansi dasar saluran yaitu perubahan dimensi penampang saluran menjadi lebih lebar dari saluran sebelumnya.

Dari data kedalaman dasar saluran dapat diketahui bahwa selama pengaliran terjadi penggerusan di sepanjang dasar saluran 2. Berikut grafik yang kami peroleh dari data pengukuran tersebut. 


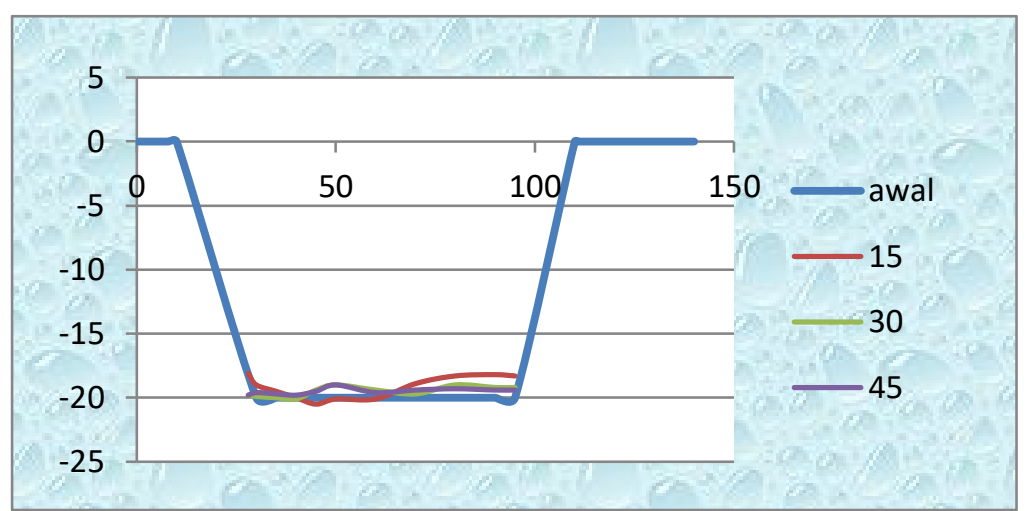

Gambar 3. Grafik kedalaman dasar saluran pada saluran 2 pada bagian hulu

\section{Kedalam dasar saluran pada saluran 3}

Kebalikan dari saluran 2, saluran 3 ini bengalami perubahan dimensi dasar saluran dari hilir saluran 2 yang berukuran $60 \mathrm{~cm}$ ke hulu saluran 3 yang berukuran 40 $\mathrm{cm}$. Dari data kedalaman dasar saluran dapat diketahui bahwa selama pengaliran terjadi penggerusan di sepanjang dasar saluran 3.

\section{Kedalam dasar saluran pada saluran 4}

Pada saluran 4 terjadi perubahan dimensi penampang dari hilir saluran 3 yang lebarnya dasar salurannya $40 \mathrm{~cm}$ menuju hulu saluran 4 yang memiliki lebar dasar saluran $70 \mathrm{~cm}$. Serupa dengan kasus saluran 2, pada saluran ini juga terjadi ekspansi lebar dasar saluran.

Dari data kedalaman dasar saluran dapat diketahui bahwa selama pengaliran terjadi penggerusan di sepanjang dasar saluran 4. Adapun grafik yang kami peroleh dari data pengukuran tersebut, dapat dilihat pada gambar di bawah ini.



Gambar 4. Grafik kedalaman dasar saluran pada saluran 4 pada bagian hulu

\section{Angkutan sedimen dasar (qb)}

Dengan memperhatikan gerakan sedimen di dasar dan melihat grafik dasar saluran di atas, dapat kita ketahui bahwa terdapat sejumlah sedimen yang mengalir di dasar saluran. Besarnya agkutan sedimen yang terjadi dipengaruhi oleh tegangan geser yang terjadi di dasar saluran. Sehingga pada tiap penampang, besar angkutan dasar berbeda-beda.

Variasi tegangan geser yang terjadi pada setiap penampang mempengaruhi besarnya angkutan dasar aliran. Sehingga jika diperoleh tegangan dasar yang lebih 
besar dari tegangan kritis sedimen maka akan terjadi transportasi sedimen. Berikut diperoleh hasil perhitungan tegangan dasar yang terjadi pada setiap penampang.

Tegangan geser dasar ( $\tau 0)$ dan tegangan geser kritis ( $\tau \mathrm{cr})$

Perhitungan tegangan dasar yang terjadi di setiap penampang:

1. Penampang 1

Diketahui : $\rho=1000 \mathrm{~kg} / \mathrm{m}^{3}, \rho s=2560 \mathrm{~kg} / \mathrm{m}^{3}$

$\mathrm{\gamma}=\rho . \mathrm{g}=1000.9,8=9800 \mathrm{~kg} / \mathrm{m}^{3}$

$\gamma \mathrm{s}=\rho \mathrm{s} . \mathrm{g}=2560.9,8=25088 \mathrm{~kg} / \mathrm{m}^{3}$

$\mathrm{v}=0,65 \mathrm{~m} / \mathrm{s}, \quad k=0,001$

$\tau \mathrm{o}=k \cdot \rho \cdot \mathrm{v}^{2}$

$\tau_{0}=(0,001)(1000)(0,65)^{2}=0,4225 \mathrm{~kg} / \mathrm{m}^{2}$

untuk menghitung tegangan geser kritis digunakan persamaan Schoklitsch (1914):

( $\tau$ o) $\mathrm{cr}=\sqrt{0,20 \gamma(\gamma \mathrm{s}-\gamma) \lambda^{\prime} \mathrm{d}^{3}}\left(\mathrm{~km} / \mathrm{m}^{2}\right)$

diketahui :

$\mathrm{\gamma}=\rho . \mathrm{g}=1000.9,8=9800 \mathrm{~kg} / \mathrm{m}^{3}$

ys $=\rho s . g=2560.9,8=25088 \mathrm{~kg} / \mathrm{m}^{3}$

$\lambda^{\prime}=1, \mathrm{~d}=1,345 \mathrm{~mm}$

( $\tau$ o $) \mathrm{cr}=\sqrt{0,20 \gamma(\gamma \mathrm{s}-\gamma) \lambda^{\prime} \mathrm{d}^{3}}\left(\mathrm{~km} / \mathrm{m}^{2}\right)$

$\sqrt{0,20(9800)(25088-9800)(1)(0,001345)^{3}}$

$=0,270014 \mathrm{~kg} / \mathrm{m}^{2}$

Dengan memperhatikan $\tau$ o $>\tau \mathrm{cr}$ maka sesuai ketentuan dapat diketahui bahwa pada saluran tersebut terjadi angkutan.

Tabel 2. Rekapitulasi hasil perhitungan tegangan geser dasar dan tegangan kritis $(\mathrm{t}=15$ menit $)$

\begin{tabular}{ccccccc}
\hline Saluran & $\tau \mathbf{c}(\mathbf{k g} / \mathbf{m} 2)$ & $\begin{array}{c}\boldsymbol{\tau} \mathbf{c r} \\
(\mathbf{k g} / \mathbf{m} 2)\end{array}$ & Keterangan & $\boldsymbol{\tau o}(\mathbf{l b} / \mathbf{f t 2})$ & $\boldsymbol{\tau c r}(\mathbf{l b} / \mathbf{f t} 2)$ & $\tau \mathbf{c}-\boldsymbol{\tau c r}$ \\
\hline 1 & 0.4225 & 0.270014 & $\begin{array}{c}\text { cenderung } \\
\text { tergerus }\end{array}$ & 0.086534115 & 0.055302775 & 0.0312313 \\
\hline 2 & 0.208979592 & 0.270014 & $\begin{array}{c}\text { cenderung } \\
\text { mengendap }\end{array}$ & 0.042802045 & 0.055302775 & -0.012501 \\
\hline 3 & 0.3136 & 0.270014 & $\begin{array}{c}\text { cenderung } \\
\text { tergerus }\end{array}$ & 0.064229819 & 0.055302775 & 0.008927 \\
\hline 4 & 0.16 & 0.270014 & $\begin{array}{c}\text { cenderung } \\
\text { mengendap }\end{array}$ & 0.032770316 & 0.055302775 & -0.022532 \\
\hline
\end{tabular}

Tabel 2. Rekapitulasi hasil perhitungan tegangan geser dasar dan tegangan kritis $(\mathrm{t}=30$ menit $)$

\begin{tabular}{ccccccc}
\hline Saluran & $\boldsymbol{\tau o}(\mathbf{k g} / \mathbf{m} 2)$ & $\begin{array}{c}\boldsymbol{\tau c r} \\
(\mathbf{k g} / \mathbf{m} 2)\end{array}$ & Keterangan & $\boldsymbol{\tau o}(\mathbf{l b} / \mathbf{f t} 2)$ & $\boldsymbol{\tau c r} \mathbf{( l b / f t} 2)$ & $\tau \mathbf{c}-\boldsymbol{\tau c r}$ \\
\hline 1 & 0.4225 & 0.270014 & $\begin{array}{c}\text { cenderung } \\
\text { tergerus }\end{array}$ & 0.086534115 & 0.055302775 & 0.0312313 \\
\hline 2 & 0.183673469 & 0.270014 & $\begin{array}{c}\text { cenderung } \\
\text { mengendap }\end{array}$ & 0.037618985 & 0.055302775 & -0.017684 \\
\hline 3 & 0.3364 & 0.270014 & $\begin{array}{c}\text { cenderung } \\
\text { tergerus }\end{array}$ & 0.068899589 & 0.055302775 & 0.0135968 \\
\hline
\end{tabular}




\begin{tabular}{|c|c|c|c|c|c|c|}
\hline Saluran & $\tau 0(\mathrm{~kg} / \mathrm{m} 2)$ & $\begin{array}{c}\tau \mathrm{cr} \\
(\mathrm{kg} / \mathrm{m} 2)\end{array}$ & Keterangan & $\tau 0(\mathrm{lb} / \mathrm{ft} 2)$ & $\tau \operatorname{cr}(\mathrm{lb} / \mathrm{ft} 2)$ & $\tau \mathrm{\tau}-\tau \mathrm{cr}$ \\
\hline 4 & 0.15015625 & 0.270014 & $\begin{array}{l}\text { cenderung } \\
\text { mengendap }\end{array}$ & 0.030754173 & 0.055302775 & -0.024549 \\
\hline
\end{tabular}

Tabel 3. Rekapitulasi hasil perhitungan tegangan geser dasar dan tegangan kritis $(\mathrm{t}=45$ menit $)$

\begin{tabular}{ccccccc}
\hline Saluran & $\tau \mathbf{c}(\mathbf{k g} / \mathbf{m} 2)$ & $\begin{array}{c}\boldsymbol{\tau c r} \\
(\mathbf{k g} / \mathbf{m} 2)\end{array}$ & Keterangan & $\tau \mathbf{c}(\mathbf{l b} / \mathbf{f t 2})$ & $\boldsymbol{\tau c r}(\mathbf{l b} / \mathbf{f t} 2)$ & $\tau \mathbf{c o}-\boldsymbol{\tau c r}$ \\
\hline 1 & 0.403225 & 0.270014 & $\begin{array}{c}\text { cenderung } \\
\text { tergerus }\end{array}$ & 0.082586316 & 0.055302775 & 0.0272835 \\
\hline 2 & 0.196122449 & 0.270014 & $\begin{array}{c}\text { cenderung } \\
\text { mengendap }\end{array}$ & 0.040168716 & 0.055302775 & -0.015134 \\
\hline 3 & 0.345744 & 0.270014 & $\begin{array}{c}\text { cenderung } \\
\text { tergerus }\end{array}$ & 0.070813376 & 0.055302775 & 0.0155106 \\
\hline 4 & 0.16 & 0.270014 & $\begin{array}{c}\text { cenderung } \\
\text { mengendap }\end{array}$ & 0.032770316 & 0.055302775 & -0.022532 \\
\hline
\end{tabular}

\section{Besar angkutan dasar (qb)}

Untuk mengetahui besar angkutan dasar yang terjadi pada pada saluran yang cenderung tergerus digunakan persamaan angkutan dasar Du Boy seperti di bawah ini. $\mathrm{qb}=\frac{0,173 \tau(\tau-\tau \mathrm{cr})}{\mathrm{d}^{3 / 4}}$

Dimana :

$\mathrm{qb}=$ debit angkutan dasar $\left(\mathrm{ft}^{3} / \mathrm{s}\right) / \mathrm{ft}$

$\tau$ o $\& \tau \mathrm{cr}=$ tegangan geser dasar dan tegangan geser kritis $\left(\mathrm{lb} / \mathrm{ft}^{2}\right)$

$\mathrm{d}=$ diameter butiran $(\mathrm{mm})$

Saluran $1 \mathrm{t}=15$ menit

Diketahui :

$$
\begin{aligned}
\tau \mathrm{o} & =0,086534115 \mathrm{lb} / \mathrm{ft}^{2} \\
\tau \mathrm{cr} & =0,055302775 \mathrm{lb} / \mathrm{ft}^{2} \\
\mathrm{~d} & =1,345 \mathrm{~mm} \\
\mathrm{qb} & =\frac{0,173 \tau(\tau-\tau \mathrm{cr})}{\mathrm{d}^{3 / 4}} \\
& =\frac{0,173(0,086534115)(0,086534115-0,055302775)}{(1,345)^{3 / 4}}=0,000374354\left(\mathrm{ft}^{3} / \mathrm{s}\right) / \mathrm{ft}
\end{aligned}
$$

Tabel 3. Rekapitulasi hasil perhitungan debit angkutan dasar Du Boy

\begin{tabular}{cccc}
\hline \multirow{2}{*}{ Saluran } & \multicolumn{3}{c}{ Lama Pengaliran } \\
\cline { 2 - 4 } & $\mathbf{t}=\mathbf{1 5}$ menit & $\mathbf{t}=\mathbf{3 0}$ menit & $\mathbf{t}=\mathbf{4 5}$ menit \\
\hline 1 & 0.000374354 & 0.000374354 & 0.000312114 \\
\hline 3 & 0.00007942 & 0.000129765 & 0.000152142 \\
\hline
\end{tabular}

\section{Besaranya pengendapan}

Untuk besarnya pengendapan yang terjadi, diperoleh dari tebal sedimen yang terjadi di saluran tempat mengendap untuk setiap panjang salurannya. Untuk saluran 2 
dengan lebar $30 \mathrm{~cm}$ terjadi pengendapan dengan tebal rata-rata sedimen yang mengendap $0,390 \mathrm{~cm}$. Berikut contoh perhitungan volumenya:

Untuk saluran 2 ( lebar $30 \mathrm{~cm}$ )

Dik : $\mathrm{t}=0,00390 \mathrm{~m}, 1=0,6 \mathrm{~m}, \mathrm{~L}=1,5 \mathrm{~m}$

As $=(1+\mathrm{m} . \mathrm{t}) \mathrm{t}=(0,6+1 \times 0,390) 0,390=0,002356 \mathrm{~m}^{2}$

Qs $=$ As x L $=0,002356 \mathrm{~m}^{2} \times 1,5 \mathrm{~m}=0,003534 \mathrm{~m}^{3}$

Untuk saluran 4 ( lebar $70 \mathrm{~cm}$ )

Dik : $\mathrm{t}=0,01642188 \mathrm{~m}, \mathrm{l}=0,7 \mathrm{~m}, \mathrm{~L}=1,5 \mathrm{~m}$

As $=(1+\mathrm{m} . \mathrm{t}) \mathrm{t}=(0,7+1 \times 0,01642188) 0,01642188=0,0011765 \mathrm{~m}^{2}$

Qs $\quad=$ As $\times \mathrm{L}=0,0011765 \mathrm{~m}^{2} \times 1,5 \mathrm{~m}=0,017647 \mathrm{~m}^{3}$

Dimana :

$\mathrm{t}=$ tebal rata-rata sedimen terdapkan $(\mathrm{m})$

$1=$ lebar dasar $(\mathrm{m})$

$\mathrm{L} \quad=$ Panjang saluran $(\mathrm{m})$

As = Luas permukaan melintang sedimen $\left(\mathrm{m}^{2}\right)$

Qs $\quad=$ volume sedimen $\left(\mathrm{m}^{3}\right)$

\section{KESIMPULAN}

Berdasarkan hasil penelitian yang telah dilakukan dapat diambil kesimpulan sebagai berikut :

a) Pengaruh lebar dasar sungai terhadap pola aliran yang terjadi di setiap penampang adalah berubahnya kecepatan aliran untuk setiap lebar dasar yang ditentukan. Untuk perubahan penampang lebar ke penampang yang lebih sempit terjadi peningkatan kecepatan aliran, sedangkan untuk perubahan penampang sempit ke penampang yang lebih lebar terjadi penurunan kecepatan aliran. Dengan kata lain, dengan menambah ukuran lebar dasar saluran, maka semakin kacil kecepatan aliran. Dan semakin diperkecil lebar penampang saluran, maka kecepatan aliran akan semakin besar.

b) Kecepatan aliran pada setiap penampang mempengaruhi aliran sedimen di dasar saluran. Dengan meningkatnya kecepatan aliran pada penampang maka transpor sedimen menjadi besar. Begitu pula sebaliknya, dengan menurunnya kecepatan aliran pada penampang maka cenderung terjadi pengendapan. Hal tersebut terjadi dikarenakan adanya hubungan perbandingan lurus antara kecepatan aliran dan tegangan geser di dasar saluran.

c) Besarnya angkutan dasar berbanding lurus dengan tegangan geser dasar aliran. Yaitu semakin besar tegangan geser dasar aliran maka semakin besar pula angkutan sedimen dasar.

d) Persentase gerusan yang terjadi pada saluran 1 dan 3 dengan lebar masing masing adalah $30 \mathrm{~cm}$ dan $40 \mathrm{~cm}$ adalah $0,7878 \%$ untuk lama pengaliran 15 menit. Sedangkan persentasi pengendapan yang terjadi pada saluran 2 dan 4 yang memiliki lebar masing-masing $60 \mathrm{~cm}$ dan $70 \mathrm{~cm}$. adalah 0,79972\% untuk lama pengaliran 15 menit.

DAFTAR PUSTAKA

Chow, V.T., (ed. Suyatman, dkk.). (1995). Hidraulika Saluran Terbuka. Jakarta: Erlangga. 
Cops Asisten. Edisi Kesembilan. (2010). Penuntun Praktikum Hidrolika. Jurusan Sipil Fakultas Teknik Universitas Hasanuddin.

Hanwar, S.. (1999). Gerusan Lokal di Sekitar Abutmen Jembatan. Tesis. Yogyakarta: UPPS UGM.

H.R. Mulyanto. (2006). Sungai Fungsi dan Sifat-Sifatnya. Yogyakarta: Graha Ilmu.

Kodoatie Robert,J. Edisi Revisi. (2009). Hidrolika Terapan. Yogyakarta: Andi Offset.

Legono, Djoko. (2003). Jurnal Fenomena Alamiah Erosi dan Sedimentasi Sungai Probolinggo Hilir. Semarang: Universitas Diponegoro:.

Pallu, Saleh. (2007). Diktat Kuliah Metode Penelitian Dan Penulisan Ilmiah. Makassar: Teknik Sipil Universitas Hasanuddin.

Pallu, Saleh. (2011). Diktat Sediment Transport. Makassar: Teknik Sipil Universitas Hasanuddin.

Setyono, Ernawan. (2007). Jurnal Krib Impermeabel Sebagai pelindung Pada Belokan Sungai. Malang: Universitas Muhammadiah Malang.

Sjarief, Restam. (2010). Tata Ruang Air. Yogyakarta: Andi Offset.

Sosrodarsono S. (2008). Perbaikan dan Pengaturan Sungai. Jakarta: PT. Tradnya Paramita.

Triatmodjo, B. (1993). Mekanika Fluida. Yogyakarta: Universitas Gadjah Mada.

Triatmodjo, B.. (2003). Hidraulika I. Yogyakarta: Beta Offset.

Triatmodjo, Prof Dr Ir Bambang,CES,DEA. (2008). Hidraulika II. Yogyakarta: Beta Offset.

Yuwono Nur. (1996). Perencanaan Model Hidraulik. Yogyakarta: Universitas Gadjah Mada. 
PENA TEKNIK: Jurnal Ilmiah Ilmu-Ilmu Teknik

Volume 4, Nomor 1, Maret 2019 : 77- 87

Halaman ini sengaja dikosongkan 